\title{
Experimental characterization and constitutive modeling of the non-linear stress-strain behavior of unidirectional carbon-epoxy under high strain rate loading
}

Hannes Koerber ${ }^{1}$, Peter Kuhn ${ }^{1}$, Marina Ploeckl ${ }^{1}$, Fermin Otero ${ }^{2,3}$, Paul-William Gerbaud ${ }^{4}$, Raimund Rolfes ${ }^{5}$ and Pedro P. Camanho ${ }^{2,6^{*}}$ (D)

${ }^{*}$ Correspondence: pcamanho@fe.up.pt ${ }^{6}$ DEMec, Faculdade de Engenharia, Universidade do Porto, Rua Dr. Roberto Frias 400, 4200-465 Porto, Portugal

Full list of author information is available at the end of the article

\begin{abstract}
The mechanical response of IM7-8552 carbon epoxy was investigated for transverse tension and transverse tension/in-plane shear loadings at static and dynamic strain rates using transverse tension and off-axis tension specimens. The dynamic tests were carried out on a split-Hopkinson tension bar at axial strain rates from 113 to $300 \mathrm{~s}^{-1}$. With the already available off-axis and transverse compression test data for IM7-8552, a comprehensive data set is available now, which can be used for validation and calibration of numerical models. The measured axial stress-strain response was simulated using a fully 3D transversely isotropic elastic-viscoplastic constitutive model. The constitutive model represents a viscoplastic extension of the transversely-isotropic plasticity model developed by the authors (Vogler et al. in Mech Mater 59:50-64, 2013). An invariant based failure criterion is added to the model to be able to predict the strength for a given orientation and strain rate accurately. The strain rate dependency of the elastic and ultimate strength properties is introduced in the model through scaling functions. A good correlation between the measured and numerically predicted stress-strain response and failure of the specimens was achieved for all specimen types and both strain rate regimes.
\end{abstract}

Keywords: Composites, Carbon-epoxy, Strain rate effects, Viscoplasticity, Constitutive modeling

\section{Introduction}

Over the past years, the number of applications in which fiber reinforced polymer matrix composites (FRPMCs) are used in primary aeronautical (e.g. Airbus A350 and Boeing 787) and automotive (e.g. BMW i-project) structures has significantly increased. In both areas, composite structures may be subjected to high speed loading events and the simulation of the dynamic material response is therefore relevant for several loading scenarios, such as bird, tire and hail impact and crash.

(c) The Author(s) 2018. This article is distributed under the terms of the Creative Commons Attribution 4.0 International License (http://creativecommons.org/licenses/by/4.0/), which permits unrestricted use, distribution, and reproduction in any medium, provided you give appropriate credit to the original author(s) and the source, provide a link to the Creative Commons license, and indicate if changes were made. 
Strain rate effects and non-linear stress-strain behavior should be captured by advanced composite material models to accurately predict the initiation and evolution of damage. This requires not only appropriate material models but also new experimental techniques for model identification and validation.

In the experimental part of this work the mechanical response of a UniDirectional (UD) carbon-epoxy composite is investigated under transverse tension and combined transverse tension/in-plane shear loading at quasi-static and dynamic strain rates. The presented test data complements static and dynamic experimental results from earlier and recent studies for the same material system, namely [2], where off-axis compression and transverse compression tests were performed [3,4], where the longitudinal compressive response was studied and [5], where the effect of dynamic loading was investigated for the intralaminar fracture toughness associated with fiber compressive failure.

In the numerical part of this work the available tension and compression tests are simulated using a new fully 3D transversely isotropic elastic-viscoplastic constitutive model, which is able to predict the experimentally observed nonlinearities under off-axis loading prior to the onset of cracking [1]. The strain-rate dependency of the plastic yields, the elastic response and the ultimate strength is accurately taken into account.

It is understood that the mechanical behavior of a multidirectional laminate may differ from the mechanical response of a UD laminate or ply. In particular crack initiation and propagation in a multidirectional laminate strongly depends on the fiber orientation, thickness and stacking sequence of the individual plies in the laminate. The numerical model presented in this paper is used and has been validated with experimental data from unidirectional laminates. Further work is required to enhance and validate the herein presented model to also predict the mechanical response of arbitrary multidirectional laminates under static and high strain rate loading.

\section{Experimental work}

\section{Material and specimens}

Quasi-static and dynamic off-axis tension and transverse tension tests were carried out, using the UD prepreg system IM7-8552. While being a high performance prepreg material system often used for primary composite structures, this toughened-epoxy composite exhibits considerable non-linear stress-strain behavior, which is used here to verify the proposed constitutive material model. In accordance with the specified heating cycle, a UD panel with a nominal thickness of $1.5 \mathrm{~mm}$ was manufactured by curing a 12-ply prepreg layup in a hot press. From the manufactured panel, off-axis tension specimens with fiber orientation angles of $\theta=15^{\circ}, 30^{\circ}$ and $45^{\circ}$ and transverse tension specimens $\left(\theta=90^{\circ}\right)$ were cut on a water-cooled diamond saw.

The nominal dimensions of the $15^{\circ}$ off-axis specimens were $72 \times 8 \times 1.5 \mathrm{~mm}^{3}$ and 62 $\times 8 \times 1.5 \mathrm{~mm}^{3}$ for all other specimens (Fig. 1a).

To attach the specimens to the split-Hopkinson tension bar system, slotted steel adapters with an M12 $\times 1.25$ outside thread were manufactured. The rectangular composites specimens were then glued into the adapters using the structural adhesive 3M Scotch-Weld DP490 (Fig. 1b).

The 12-ply UD laminate with a thickness of $1.5 \mathrm{~mm}$ was chosen to guarantee that the ultimate load of the strongest specimen (high strain rate test of the $15^{\circ}$ off-axis tension 


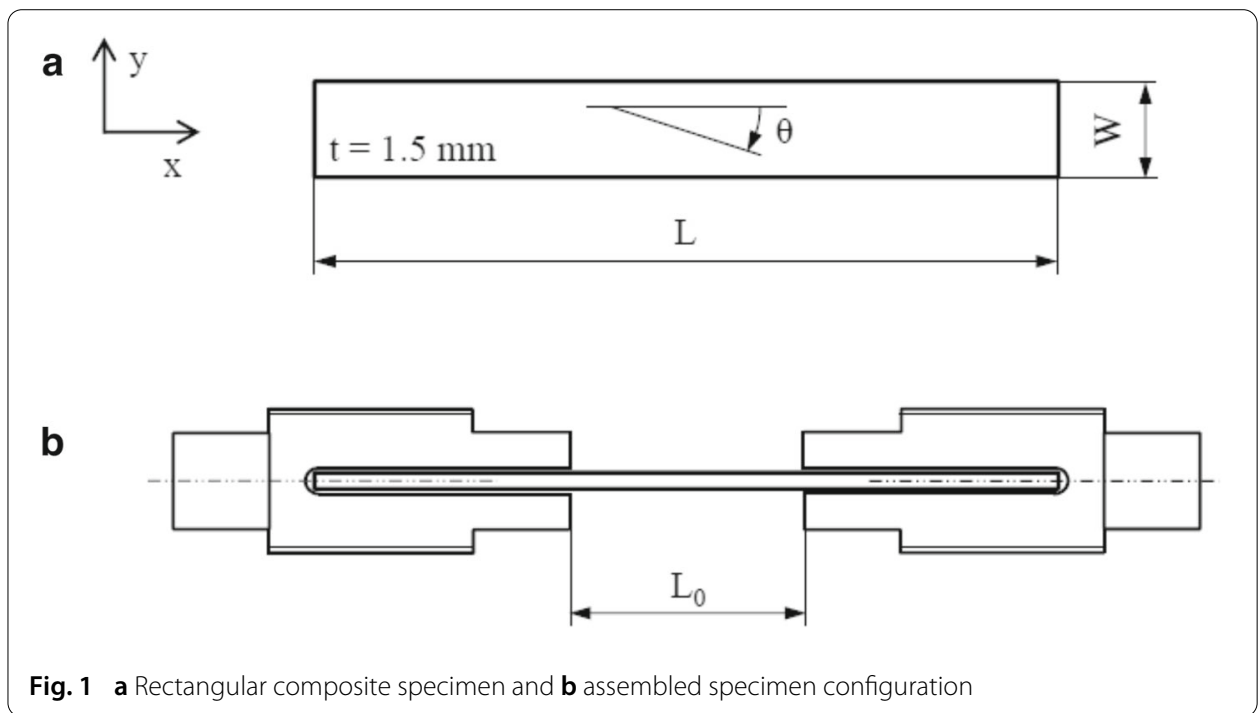

specimen) can be transmitted through the bond in the adapters and that failure occurs in the free gauge section of the specimen instead of the bond.

The dimension of the free specimen length $\mathrm{L}_{0}$ between the two adapters was chosen to obtain a section where no fiber is attached to either of the two adapters. Thus for the $15^{\circ}$ off-axis specimens $\mathrm{L}_{0}=30 \mathrm{~mm}$ was used, while for all other specimens $L_{0}=20 \mathrm{~mm}$ was found to be sufficient.

\section{Quasi-static and dynamic test setup}

The quasi-static tests were performed on a standard electro-mechanical testing machine (Hegewald \& Peschke Inspect Table 100). The adapters of the assembled specimens were screwed into inserts, which in turn were connected to the test machine (Fig. 2). A constant displacement rate of $0.5 \mathrm{~mm} \mathrm{~min}^{-1}$, which is in the range of a typical test velocity recommended for quasi-static testing, was chosen and the GOM ARAMIS-4M DIC system was used to measure the in-plane strain field of the free specimen length.

The high strain rate tests were carried out on a split-Hopkinson tension bar (SHTB) system. The setup, illustrated in Fig. 3, is based on a concept proposed in [6], using a U-

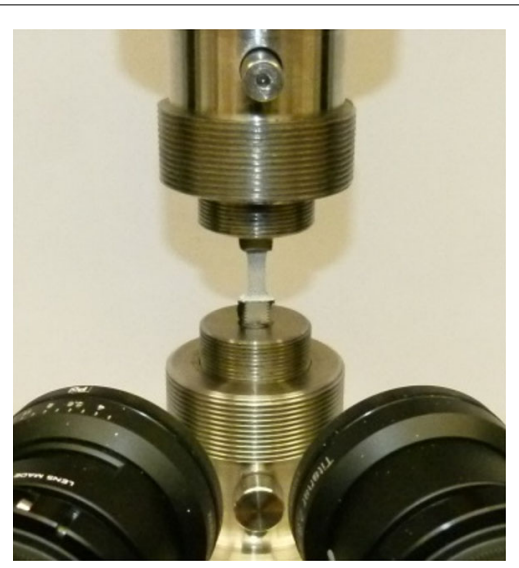

Fig. 2 Quasi-static test setup 


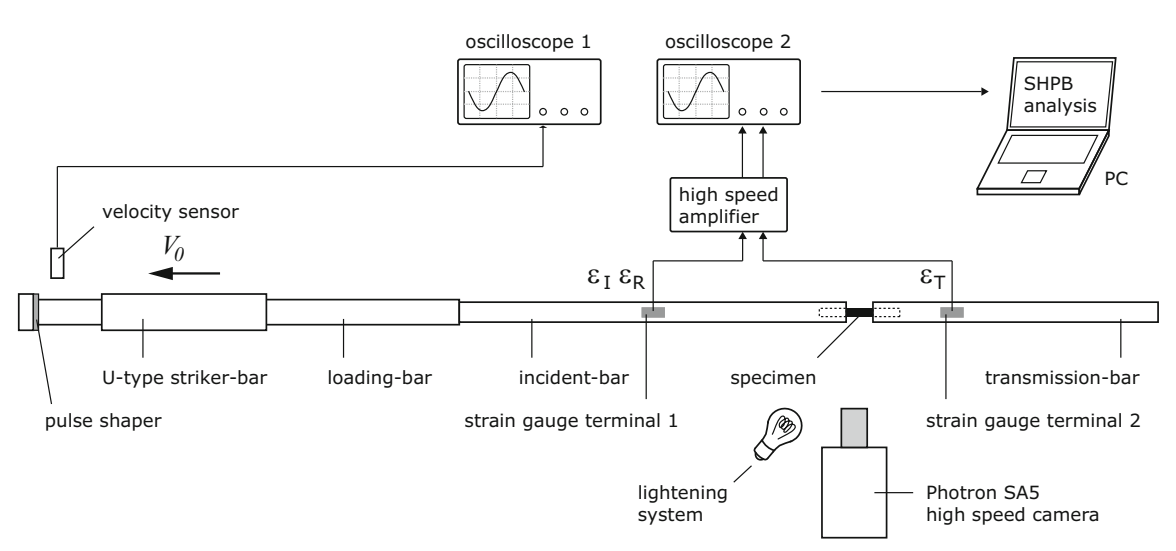

Fig. 3 Split-Hopkinson tension bar setup for dynamic tests (striker-bar acceleration system not shown)

shaped striker-bar. The bars consisted of $\varnothing 20 \mathrm{~mm}$ titanium loading-, $\varnothing 16 \mathrm{~mm}$ incidentand $\varnothing 16 \mathrm{~mm}$ transmission-bars with lengths of $2.15,3$ and $1.8 \mathrm{~m}$, respectively.

Rings of $2 \mathrm{~mm}$ thick silicon rubber, wrapped around the impact flange at the end of the loading bar, were used for pulse shaping. The resulting ramp-shaped pulse was ideally suited for the pre-dominantly linear stress-strain behavior expected for the dynamic test, due to the relatively low plastic strains measured during the quasi-static tests.

From a previous study [2] is was observed that, depending on the off-axis angle, the strain rate acting in the fracture plane of the off-axis specimens can be significantly higher than the strain rate applied in axial (loading) direction. For an accurate comparison of the strain rate effect, the strain rates acting in the fracture plane should be similar for all tested specimen types. In this work, the strain rate in the loading direction was therefore increased with increasing off-axis angle in order to capture the corresponding shift from an in-plane shear to a transverse tensile material response. To reach a shear strain rate of $350 \mathrm{~s}^{-1}$ in the fracture plane of the respective off-axis specimens, the axial strain rate for the $15^{\circ}, 30^{\circ}$ and $45^{\circ}$ off-axis specimens was adjusted to approximately 110, 180 and $300 \mathrm{~s}^{-1}$, respectively. For the transverse tension specimens, the axial strain rate is the governing value. Due to the striker-bar velocity of the used split-Hopkinson tension bar system, together with the chosen specimen geometry, the average attainable strain rate for the $90^{\circ}$ specimens was $271 \mathrm{~s}^{-1}$ and was therefore slightly lower.

For each specimen type and strain rate regime, three valid tests were performed. To obtain the specimen strain field via DIC, the deformation of the specimen was monitored by a Photron SA5 high speed camera. The chosen camera parameters are listed in Table 1.

Table 1 Setup parameters of high speed camera

\begin{tabular}{lll}
\hline Specimen type & Frames per second $\left(\mathbf{s}^{\mathbf{- 1}}\right)$ & Resolution ( $\left.\mathbf{p i x e l}^{\mathbf{2}}\right)$ \\
\hline $15^{\circ}$ & 186.000 & $392 \times 96$ \\
$30^{\circ}$ & 186.000 & $256 \times 112$ \\
$45^{\circ}$ & 300.000 & $192 \times 80$ \\
$90^{\circ}$ & 300.000 & $192 \times 80$ \\
\hline
\end{tabular}




\section{Data reduction}

For the quasi-static transverse and off-axis tension tests presented in this paper, true axial stress $\sigma_{x x}$ was calculated by dividing the load $F$, measured from the load-cell of the test machine, by the true cross-section $A_{s}$ of the specimen. $A_{s}$ was determined from the initial cross-section $A_{s 0}$, the initial specimen length $l_{s 0}$ and the true specimen length $l_{s}$ by applying the volume consistency condition as described in [7]. Similarly, true axial stress $\sigma_{x x}$ was determined for the dynamic tests, following classic split-Hopkinson pressure bar analysis (SHPBA) [8] as

$$
\sigma_{x x}=A_{b} E_{b} \varepsilon_{T} / A_{s}
$$

where $A_{b}, E_{b}$ and $\varepsilon_{T}$ are the cross-section, Young's modulus and the measured elastic strain wave of the transmission bar.

The in-plane strain field $\left\{\varepsilon_{x x}, \varepsilon_{y y}, \gamma_{x y}\right\}^{T}$ in the load coordinate system was obtained via DIC, averaging the respective strain components over an area of $5 \times 5 \mathrm{~mm}^{2}$ in the specimen centre. Engineering strain was determined from the DIC measurements. The strain component in loading direction was further used for the calculation of the axial specimen strain rate $\dot{\varepsilon}_{x x}$ with respect to time:

$$
\dot{\varepsilon}_{x x}=d \varepsilon_{x x} / d t
$$

The static and dynamic in-plane shear stress-strain curves from the respective off-axis tension tests, required as input for the later described constitutive model, were calculated by applying a standard coordinate transformation to the axial stress and strain vector, measured in the load coordinate system as

$$
\begin{aligned}
& \tau_{12}=-\sigma_{x x} \sin \beta \cos \beta \\
& \gamma_{12}=-\varepsilon_{x x} \sin 2 \beta+\varepsilon_{y y} \sin 2 \beta+\gamma_{x y} \cos 2 \beta .
\end{aligned}
$$

The transformation angle $\beta$ consisted of the initial off-axis angle $\theta$ and the fiber rotation angle $d \theta$, which occurs due to the extension-shear coupling effect in the off-axis specimens and which can be measured via DIC as well. For the off-axis tension tests, the fibers in the UD laminate tend to rotate towards the loading direction and therefore the transformation angle was obtained as

$$
\beta=\theta_{0}-d \theta
$$

The shear strain rate $\dot{\gamma}_{12}$ was calculated analogous as the axial strain rate by derivation of Eq. (4) with respect to time:

$$
\dot{\gamma}_{12}=d \gamma_{12} / d t
$$

\section{Experimental results}

The axial stress-strain curves of the off-axis tension and transverse tension specimens for both strain rate regimes are shown together with the predictions of the numerical model in "Results" section, Figs. 12, 13, 14 and $15 .^{1}$

${ }^{1}$ It is noted that the experimental results of the off-axis and transverse tension tests were first shown in [9]. Due to a later improved calibration of the split-Hopkinson tension bar, the stresses had to be corrected and were about $5 \%$ lower than initially presented in [9]. For completeness, the corrected data is used in this work for Table 2, Figs. 4, 12, 13, 14, $15,16,17,18,19,20$ and 21. 
All off-axis tension loaded specimens show non-linear stress-strain behavior at quasistatic loading and a tendency to more linear stress-strain curves under dynamic loading. For the transverse tensile specimens, the stress-strain behavior is linear at both strain rate regimes (see Fig. 15).

A pronounced strain rate effect on the axial strength was measured for all specimen configurations. The strengths increase by $38,28,30$ and $27 \%$ for the $15^{\circ}, 30^{\circ}, 45^{\circ}$ and $90^{\circ}$ specimens, respectively, and therefore a similar strain rate effect was found. The measured properties are summarised in Table 2.

The quasi-static and dynamic in-plane shear behavior derived from the $15^{\circ}, 30^{\circ}, 45^{\circ}$ offaxis specimens via Eqs. (3) and (4) can be seen for representative specimens in Fig. 4. From the available static and dynamic experimental results it is a reasonable approximation to define a master shear curve, which resembles the in-plane shear response for combined in-plane shear and transverse tensile loading for all off-axis angles tested in the current work. The overall shape of this master shear stress-strain curve is therefore independent of the respective off-axis angle, while the shear strength for the combined stress state is significantly affected by the amount of transverse stress, also acting on the fracture plane. A similar behavior was observed for the in-plane shear response reported in [2].

For the transverse tension specimens, pronounced scatter in the measured strength was found for both strain rate regimes. Nevertheless, the calculated mean value for quasi-static loading coincides well with the transverse strength listed in the HexPly IM7-8552 material data sheet [10].

Table 2 Quasi-static and high rate off-axis tension and transverse tension properties

\begin{tabular}{|c|c|c|c|c|c|c|}
\hline & $\begin{array}{l}\text { Fiber angle } \\
\boldsymbol{\theta}\left(^{\circ}\right)\end{array}$ & & $\begin{array}{l}\text { Ultimate } \\
\text { strength (MPa) }\end{array}$ & $\begin{array}{l}\text { Shear angle } \\
\mathbf{d} \boldsymbol{\theta}\left(^{\circ}\right)\end{array}$ & $\begin{array}{l}\text { Axial strain } \\
\text { rate } \dot{\varepsilon}_{x x}\left(s^{-1}\right)\end{array}$ & $\begin{array}{l}\text { Shear strain } \\
\text { rate } \dot{\gamma}_{12}\left(\mathrm{~s}^{-1}\right)\end{array}$ \\
\hline \multirow[t]{12}{*}{ Quasi-static } & 15 & Mean & 364 & 1.56 & $2.1 \cdot 10^{-4}$ & $7.8 \cdot 10^{-4}$ \\
\hline & & STDV & 27.7 & 0.32 & $2.8 \cdot 10^{-5}$ & $1.8 \cdot 10^{-4}$ \\
\hline & & CV (\%) & 7.6 & 20.5 & 13.3 & 15.3 \\
\hline & 30 & Mean & 175 & 0.82 & $2.9 \cdot 10^{-4}$ & $6.0 \cdot 10^{-4}$ \\
\hline & & STDV & 12.5 & 0.09 & $7.7 \cdot 10^{-6}$ & $4.2 \cdot 10^{-5}$ \\
\hline & & CV (\%) & 7.2 & 11.0 & 2.7 & 7.0 \\
\hline & 45 & Mean & 114 & 0.35 & $2.6 \cdot 10^{-4}$ & $3.8 \cdot 10^{-4}$ \\
\hline & & STDV & 9.5 & 0.03 & $2.9 \cdot 10^{-5}$ & $3.3 \cdot 10^{-5}$ \\
\hline & & CV (\%) & 8.3 & 8.6 & 11.3 & 8.6 \\
\hline & 90 & Mean & 62 & - & $2.8 \cdot 10^{-4}$ & - \\
\hline & & STDV & 14.0 & - & $1.7 \cdot 10^{-5}$ & - \\
\hline & & CV (\%) & 22.6 & - & 5.9 & - \\
\hline \multirow[t]{12}{*}{ High rate } & 15 & Mean & 503 & 1.45 & 113 & 358 \\
\hline & & STDV & 10.7 & 0.20 & 19 & 51 \\
\hline & & CV (\%) & 2.1 & 13.8 & 16.8 & 14.2 \\
\hline & 30 & Mean & 223 & 0.71 & 177 & 337 \\
\hline & & STDV & 3.3 & 0.05 & 10 & 10 \\
\hline & & CV (\%) & 1.4 & 7.0 & 5.6 & 3.0 \\
\hline & 45 & Mean & 148 & 0.34 & 300 & 410 \\
\hline & & STDV & 16.7 & 0.04 & 44 & 64 \\
\hline & & CV (\%) & 11.3 & 11.8 & 14.7 & 15.6 \\
\hline & 90 & Mean & 79 & - & 271 & - \\
\hline & & STDV & 11.9 & - & 13 & - \\
\hline & & CV (\%) & 15.1 & - & 4.8 & - \\
\hline
\end{tabular}




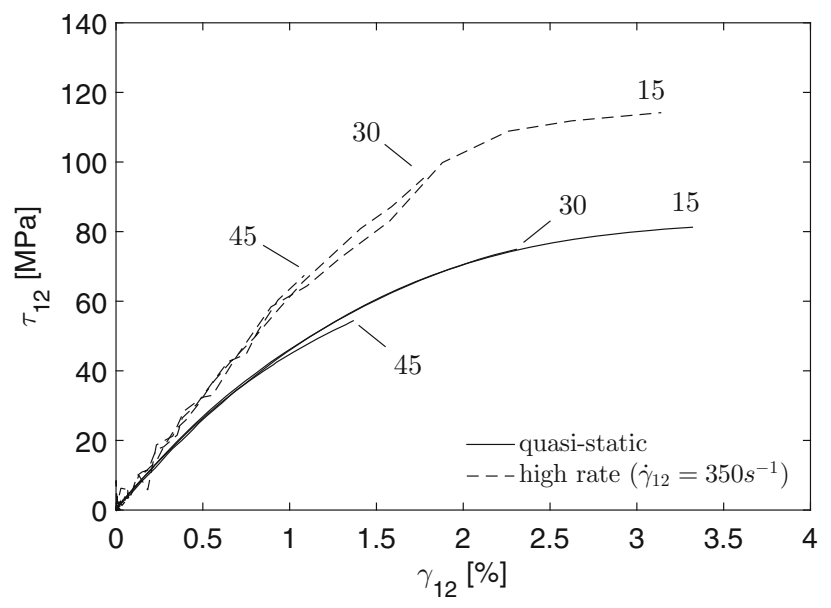

Fig. 4 In-plane shear behavior derived from off-axis tension tests (engineering stress-strain curves shown)

\section{Constitutive model}

Hereafter, the constitutive model used for the prediction of the off-axis tensile and compressive tests is briefly presented. This model represents a viscoplastic extension of the transversely isotropic elastic-plastic model proposed by Vogler et al. [1,11]. The main objective is the prediction of the pressure dependent pre-failure nonlinearities under offaxis loading conditions as they are observed in carbon epoxy composites. The model predicts the non-linear behavior of the stress-strain curve, where all non-linearity is considered to be due to plasticity. At ultimate load the failure criterion described below is applied. It is noted that the model in its current form does not contain a damage-evolution formulation, which is subject of future development and for which additional static and high strain rate experimental data is required. The material model proposed consists of an elastic-viscoplastic model, assuming the additive decomposition of the total strain tensor at the a material point, $\boldsymbol{\varepsilon}$, into the elastic $\boldsymbol{\varepsilon}_{\mathrm{e}}$ and the viscoplastic parts $\boldsymbol{\varepsilon}_{\mathrm{vp}}$,

$$
\varepsilon=\varepsilon_{\mathrm{e}}+\varepsilon_{\mathrm{vp}}
$$

The anisotropy is taken into account by structural tensors and not by symmetry conditions based on a reference coordinate system. The structural tensor represents the material symmetries of the respective anisotropy class as an intrinsic material's property and is used as additional argument in the constitutive equations. This enables a coordinate system free representation of the anisotropic material laws as isotropic tensor functions. Moreover, finite fiber rotations can be regarded easily. The structural tensor $\boldsymbol{A}$ that represents the symmetry conditions of transversely isotropic materials is defined by the dyadic product of the unit vector of the preferred (fiber) direction $\underline{a}$,

$$
A=\underline{a} \otimes \underline{a} .
$$

Following the previous work reported in [1], the structural tensor is used as an additional argument in order to formulate the elastic free energy density, the yield function and the plastic potential formulation. In the proposed elastic-viscoplastic extension $\boldsymbol{A}$ is used in the formulation of the viscoplastic creep function and the viscoplastic potential, which are 
analogous to the plastic yield function and the plastic potential, respectively. However, the model should also take into account the strain rate dependence of the elastic and strength properties observed in carbon-epoxy composites [2,12-18]. The elastic free energy density for the proposed transversely isotropic model reads:

$$
\begin{aligned}
\Psi(\boldsymbol{\varepsilon}, \dot{\boldsymbol{\varepsilon}}, \boldsymbol{A}):= & \frac{1}{2} \lambda(\dot{\boldsymbol{\varepsilon}})[\operatorname{tr}(\boldsymbol{\varepsilon})]^{2}+\mu_{T}(\dot{\boldsymbol{\varepsilon}}) \operatorname{tr}\left(\boldsymbol{\varepsilon}^{2}\right)+\alpha(\dot{\boldsymbol{\varepsilon}})[\underline{a} \boldsymbol{\varepsilon} \underline{a}] \operatorname{tr}(\boldsymbol{\varepsilon}) \\
& +2\left[\mu_{L}(\dot{\boldsymbol{\varepsilon}})-\mu_{T}(\dot{\boldsymbol{\varepsilon}})\right]\left(\underline{a} \boldsymbol{\varepsilon}^{2} \underline{a}\right)+\frac{1}{2} \beta(\dot{\boldsymbol{\varepsilon}})[\underline{a} \boldsymbol{\varepsilon} \underline{a}]^{2},
\end{aligned}
$$

with the five elasticity constants $\lambda(\dot{\boldsymbol{\varepsilon}}), \mu_{T}(\dot{\boldsymbol{\varepsilon}}), \mu_{L}(\dot{\boldsymbol{\varepsilon}}), \alpha(\dot{\boldsymbol{\varepsilon}}), \beta(\dot{\boldsymbol{\varepsilon}})$ as invariant coefficients. The coefficients are called invariants, because their values are computed outside of the user-material subroutine (before the simulation occurs), for a given global strain-rate in the material, and these values do not change during the simulation. It means that only one strain rate can be used at a time. The conversion into engineering constants and vice versa can be found in [1]. The stress tensor $\sigma$ and the elasticity tensor $\mathbb{C}_{e}$ can be obtained by computing the first and the second derivatives of the free energy density with respect to the strain tensor, respectively

$$
\sigma=\partial_{\varepsilon} \Psi, \quad \mathbb{C}_{e}=\partial_{\varepsilon \varepsilon}^{2} \Psi .
$$

To formulate the transversely isotropic invariants used in the viscoplastic creep function, a decomposition of the stress in viscoplasticity inducing stresses and elastic reaction stresses is used:

$$
\sigma=\sigma_{\text {reac }}+\sigma_{\text {vpind }}
$$

where the elastic reaction and viscoplasticity inducing stresses are defined as [1]:

$$
\begin{aligned}
\sigma_{\text {reac }} & =\frac{1}{2}(\operatorname{tr} \sigma-\underline{a} \sigma \underline{a}) \mathbf{1}-\frac{1}{2}(\operatorname{tr} \sigma-3 \underline{a} \sigma \underline{a}) A, \\
\sigma_{\text {vpind }} & =\sigma-\sigma_{\text {reac }}
\end{aligned}
$$

The set of invariants used to formulate the viscoplastic creep surface reads:

$$
\begin{aligned}
& \mathrm{I}_{1}=\frac{1}{2} \operatorname{tr}\left(\sigma_{\text {vpind }}^{2}\right)-\underline{a}\left(\sigma_{\text {vpind }}^{2}\right) \underline{a}, \\
& \mathrm{I}_{2}=\underline{a} \sigma_{\text {vpind }}^{2} \underline{a}, \\
& \mathrm{I}_{3}=\operatorname{tr}(\sigma)-\underline{a} \sigma_{\text {vpind }} \underline{a} .
\end{aligned}
$$

Using the invariants defined in Eq. (13), the transversely isotropic viscoplastic creep surface for UD composites reads [1]:

$$
f\left(\boldsymbol{\sigma}, \bar{\varepsilon}_{\mathrm{vp}}, \boldsymbol{A}\right)=\alpha_{1} \mathrm{I}_{1}+\alpha_{2} \mathrm{I}_{2}+\alpha_{3} \mathrm{I}_{3}+\alpha_{32} \mathrm{I}_{3}^{2}-1 \leq 0,
$$

where

$$
\begin{array}{ll}
\alpha_{3}=\alpha_{3}^{t} \alpha_{32}=\alpha_{32}^{t} & \text { if } \mathrm{I}_{3}>0, \\
\alpha_{3}=\alpha_{3}^{c} \alpha_{32}=\alpha_{32}^{c} & \text { if } \mathrm{I}_{3} \leq 0,
\end{array}
$$

and the equivalent viscoplastic strain defined as

$$
\bar{\varepsilon}_{\mathrm{vp}}=\sqrt{\frac{1}{2}\left(\varepsilon_{\mathrm{vp}}\right)_{i j}\left(\varepsilon_{\mathrm{vp}}\right)_{i j}} .
$$


The proposed viscoplastic creep function results in 6 viscoplastic creep $\alpha$-parameters that have to be determined. Each one of these parameters and the corresponding invariants are related to the following loading states: transverse shear, in-plane shear, uniaxial and biaxial transverse tension and uniaxial and biaxial transverse compression. Figure 5 shows a schematic representation of the transversely isotropic $f$ surface in stress space. The points represented in the curves are the "trigger points of the viscoplastic creep surface, for a given strain rate, in which viscoplastic process is controlled. That is, in each of these points, an initial yield stress and a hardening curve giving the yield stress vs. the corresponding equivalent viscoplastic strain is defined via tabulated data. Consequently, the viscoplastic creep surface parameters $\alpha_{(\ldots)}$ are a function not only of the strain rate [2] but also of the equivalent viscoplastic strain, see [1].

The strain rate dependency of the elastic and ultimate strength properties is introduced in the present model by fitting the experimental data using suitable scaling functions. Then, the material property for a given strain rate is the quasi-static one multiplied by the scaling function. A simple function i.e. $f(\dot{\boldsymbol{\varepsilon}})=1+\sqrt{K \dot{\boldsymbol{\varepsilon}}}$, where the rate dependency of the properties depends on an appropriate selection of the parameter $K$ was proposed by Wiegand [19].

In the present work, the scaling function used by Koerber [20] is implemented

$$
f_{i}(\dot{\boldsymbol{\varepsilon}})=1+\left(K_{i} \dot{\boldsymbol{\varepsilon}}\right)^{\frac{1}{n_{i}}}
$$

where the subscript $i$ refers to the property adjusted by the function. Considering the experimental data from the available transverse and off-axis compression tests for UD carbon-epoxy IM7-8552, backed up by data from the literature for similar thermoset composites, Koerber [20] observed a different strain rate dependency for the elastic and ultimate strength properties. In particular for the elastic moduli, a threshold strain rate at about $100 \mathrm{~s}^{-1}$ appears to exist, after which the strain rate dependency of the respective elastic properties significantly increased. For the ultimate strengths, such a threshold was found to be not as pronounced and measurable strain rate effects can already be observed at lower strain rates. To account for this difference in the strain rate dependency of the elastic and ultimate strength properties, two scaling functions are used for the UD carbon-epoxy composite considered in this paper. A function $f_{e}(\dot{\boldsymbol{\varepsilon}})$ to describe the strain rate effect on the elastic and a function $f_{u}(\dot{\boldsymbol{\varepsilon}})$ to describe the strain rate effect on the
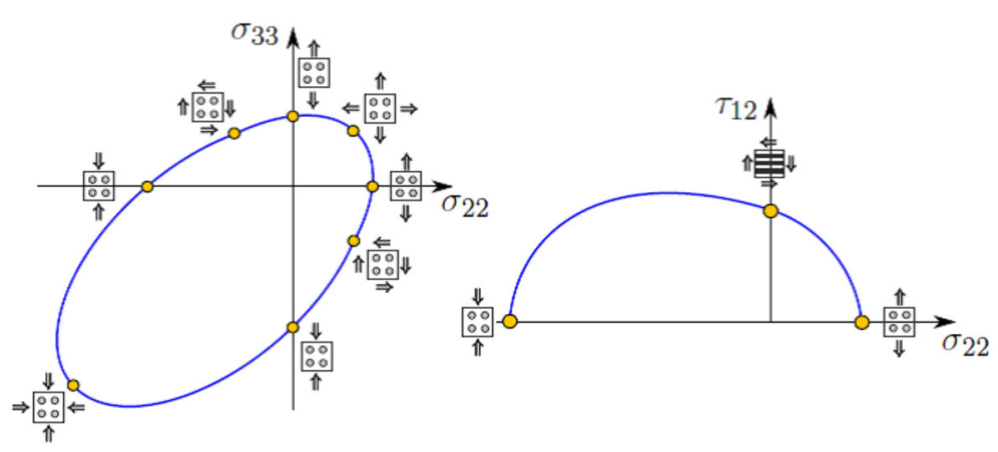

Fig. 5 Schematic representation of the yield surface for UD composites in stress space 
ultimate strength properties. The evolution of the viscoplastic strain is defined by using the following viscoplastic flow:

$$
\dot{\boldsymbol{\varepsilon}}_{\mathrm{vp}}=\dot{\gamma}_{\mathrm{vp}} \partial_{\boldsymbol{\sigma}} \mathrm{g}(\boldsymbol{\sigma}, \boldsymbol{A})=\dot{\gamma}_{\mathrm{vp}} \boldsymbol{n}_{\mathrm{g}}=\frac{\left\langle f\left(\boldsymbol{\sigma}, \bar{\varepsilon}_{\mathrm{vp}}, \boldsymbol{A}\right)^{m}\right\rangle}{\eta} \boldsymbol{n}_{\mathrm{g}},
$$

where $\dot{\gamma}_{\mathrm{vp}}$ is a non-negative parameter, known as the consistency parameter, $\mathrm{g}(\boldsymbol{\sigma}, \boldsymbol{A})$ is the function of viscoplastic potential which defined the non-associated viscoplastic flow direction $\mathbf{n}_{\mathrm{g}}$, analogous to plasticity. The choice of a non-associated flow rule for the plasticity model [1] allows the accurate prediction of the plastic Poisson coefficients and of the volumetric plastic strains. The viscoplastic potential is defined as

$$
\mathrm{g}(\boldsymbol{\sigma}, \boldsymbol{A})=\beta_{1} \mathrm{I}_{1}+\beta_{2} \mathrm{I}_{2}+\beta_{3} \mathrm{I}_{3}^{2}-1,
$$

where the viscoplastic potential parameters $\beta_{(. . .)}$are determined to achieve a certain Poisson coefficient [1,21]. From the experimental data presented in [2] is observed that the Poisson's ratios are not affected by the strain rate, then it is not needed a scaling function to take into account strain rate effects. Consequently, the viscoplastic potential parameters $\beta_{(. . .)}$are equal to the plastic potential parameters, which were already calibrated in [1] for the material used here.

The viscoplastic parameter $\dot{\gamma}_{\mathrm{vp}}$ plays a similar role to the plastic consistency parameter used in plasticity, but in this case its definition is more general

$$
\dot{\gamma}_{\mathrm{vp}}=\frac{\left\langle\Phi\left[f\left(\sigma, \bar{\varepsilon}_{\mathrm{vp}}, \boldsymbol{A}\right)\right]\right\rangle}{\eta}
$$

where $\Phi\left[f\left(\sigma, \bar{\varepsilon}_{\mathrm{vp}}, \boldsymbol{A}\right)\right]$ is the overstress function introduced by Perzyna [22], and $\eta$ is the viscosity parameter, which has the unit Ns/ $\mathrm{mm}^{2}$. The overstress function can be defined in two ways [23],

$$
\Phi\left[f\left(\boldsymbol{\sigma}, \bar{\varepsilon}_{\mathrm{vp}}, \boldsymbol{A}\right)\right]= \begin{cases}f^{m}\left(\boldsymbol{\sigma}, \bar{\varepsilon}_{\mathrm{vp}}, \boldsymbol{A}\right) & \text { Perzyna model, } \\ f\left(\boldsymbol{\sigma}, \bar{\varepsilon}_{\mathrm{vp}}, \boldsymbol{A}\right) & \text { Duvaut-Lyons model }\end{cases}
$$

where $m$ is a dimensionless exponent parameter to be defined accordingly to the material type, which can be used to model the nonlinear strain rate dependent behavior.

〈.) represent the Macaulay brackets such that:

$$
\langle\Phi(f)\rangle= \begin{cases}\Phi(f) & \text { if } \Phi(f) \geq 0 \\ 0 & \text { if } \Phi(f)<0 .\end{cases}
$$

The crucial difference with the rate independent case is that now stress states outside of the yield locus are admissible. That is, the stresses can exceed the yield surface depending on the loading velocity and are not supposed to remain on the yield locus during plastic loading, whereby the viscosity parameter acts as delay parameter. The discretized flow rule reads at $t=t^{n+1}$

$$
\frac{\Delta \gamma_{\mathrm{vp}}^{n+1}}{\Delta t^{n+1}}=\frac{\left\langle f^{m}\left(\boldsymbol{\sigma}, \overline{\boldsymbol{\varepsilon}}_{\mathrm{vp}}, \boldsymbol{A}\right)\right\rangle}{\eta}
$$


with

$$
\Delta t^{n+1}=t^{n+1}-t^{n}
$$

The viscoplastic creep function $f$ can be expressed as $f\left(\Delta \gamma_{\mathrm{vp}}^{n+1}\right)$. Therefore the consistency condition Eq. (23) can be solved for the variable $\Delta \gamma_{\mathrm{vp}}^{n+1}$ with the Newton-Raphson method, whereby the residual in a non-iterated step $(\mathrm{k})$ reads:

$$
\left.\mathrm{R}_{\mathrm{vp}}^{n+1}\right|^{(k)}:=f^{m}\left(\left.\Delta \gamma_{\mathrm{vp}}^{n+1}\right|^{(k)}\right)-\eta \frac{\left.\Delta \gamma_{\mathrm{vp}}^{n+1}\right|^{(k)}}{\Delta t^{n+1}}
$$

The residual Eq. (25) is developed into Taylor series at the end of the time step $t^{n+1}$ and linearised:

$$
\operatorname{Lin}\left[\left.\mathrm{R}_{\mathrm{vp}}^{n+1}\right|^{(k)}\right]=f^{m}-\eta \frac{\left.\Delta \gamma_{\mathrm{vp}}^{n+1}\right|^{(k)}}{\Delta t^{n+1}}+\left.\Delta^{2} \gamma_{\mathrm{vp}}^{n+1}\right|^{(k)} \frac{\partial\left(f^{m}-\eta \cdot\left[\left.\Delta \gamma_{\mathrm{vp}}^{n+1}\right|^{(k)} / \Delta t^{n+1}\right]\right)}{\left.\partial \Delta \gamma_{\mathrm{vp}}^{n+1}\right|^{(k)}}
$$

The root of the linearised residual reads:

$$
\left.\Delta^{2} \gamma_{\mathrm{vp}}^{n+1}\right|^{(k)}=-\frac{f^{m}-\eta \cdot\left[\left.\Delta \gamma_{\mathrm{vp}}^{n+1}\right|^{(k)} / \Delta t^{n+1}\right]}{m \cdot f^{m-1} \cdot\left[\partial f /\left.\partial \Delta \gamma_{\mathrm{vp}}^{n+1}\right|^{(k)}\right]-\left[\eta / \Delta t^{n+1}\right]}
$$

With the root of the linearised residual, the consistency parameter $\Delta \gamma_{\mathrm{vp}}^{n+1}$ can be updated until the consistency condition Eq. (23) is fulfilled. Finally, the viscoplastic strains $\varepsilon_{\mathrm{vp}}^{n+1}$ can be updated at the end of the current time step.

\section{Failure criterion}

To predict the failure in the composite, an Invariant based Quadratic failure criterion (IQC) based on the work of Vogler et al. [11,24] has been implemented in the model. The IQC proposes a criterion for transverse and longitudinal failure. In order to predict matrix-dominated failure mechanisms, a formulation based on the transversely isotropic yield function is proposed. The failure condition formulation is:

$$
r_{\text {matrix }}(\boldsymbol{\sigma}, \boldsymbol{A})=\kappa_{1} \mathrm{I}_{1}+\kappa_{2} \mathrm{I}_{2}+\kappa_{3} \mathrm{I}_{3}+\kappa_{32} \mathrm{I}_{3}^{2}-1,
$$

where

$$
\begin{array}{ll}
\kappa_{3}=\kappa_{3}^{t} \kappa_{32}=\kappa_{32}^{t} & \text { if } \mathrm{I}_{3}>0, \\
\kappa_{3}=\kappa_{3}^{c} \kappa_{32}=\kappa_{32}^{c} & \text { if } \mathrm{I}_{3} \leq 0 .
\end{array}
$$

The $\kappa$-parameters are obtained the same way as the $\alpha$-parameters used in Eq. (14) but using the ultimate strengths values instead of the yield strengths.

The longitudinal failure criterion predicts fiber-dominated failure mechanism, which is expected to be a brittle behavior, and it is formulated as 


$$
r_{\text {fiber }}(\sigma, A)=\frac{\underline{a} \sigma \underline{a}}{X}-1
$$

where $X$ is either the fiber tensile ultimate strength $\left(X_{T}\right)$ or the fiber compressive ultimate strength $\left(X_{C}\right)$ depending on the loading conditions. The $\underline{a} \sigma \underline{a}$ is the projection of the stress state onto the preferred direction, which is the fiber direction.

When $r=\max \left[r_{\text {matrix }}, r_{\text {fiber }}\right]$ reaches a value of zero (i.e. $r_{\text {matrix }}(\sigma, A)=0$ or $r_{\text {fiber }}(\sigma, A)=$ 0 ), it means that one of the failure conditions is fulfilled and then, the material fails completely. These two failure conditions allow the model to predict the ultimate strength in the composite and also to differentiate which component-dominated failure mechanism happens first.

The IQC is tested with the parameters given in Table 3. The transverse shear strength is assumed identical to the transverse tensile strength for the same reasons as evoked by Camanho et al. in [24].

On Fig. 6 can be seen the experimental failure surfaces for both quasi-static and dynamic compression and tensile tests (blue and pink crosses)t. Also shown in that figure are the failure surfaces predicted by the IQC, both quasi-static and dynamic loadings. They were plotted assuming values of the scale function of $f_{u}$ (quasi-static) $=1.0$ and $f_{u}$ (dynamic) $=$ 1.4 accordingly to the experimental results (see "Calibration of the scaling functions" section).

Red and yellow crosses indicate the simulated failure points using one specimen-sized single element and confirm the proper functioning of the criterion in the finite elements code by matching the IQC surfaces. The tiny variation between the plotted IQC surfaces and the simulated points is due to the use of the scaling functions (for the $15^{\circ}$ tensile test as an example, the strain rates led to $f_{u}\left(4 \cdot 10^{-4} \mathrm{~s}^{-1}\right)=1.0146$ for the quasi-static tests, $f_{u}\left(122 \mathrm{~s}^{-1}\right)=1.3427$, for the dynamic tests) which modifies the strength parameters in each case (different loading speeds) while the surfaces are computed for one value of $f_{u}$ each.

In "Results" section are shown the failure points simulated on stress-strain diagrams using another mesh. But it can already be foreseen that there will be an underestimation of the strength for the compression tests for $45^{\circ}, 60^{\circ}$ and $75^{\circ}$ specimens because of the shape of the IQC surface.

The IQC uses the same formulation as the yield criterion for the matrix failure which leads to similar shaped yield and failure surface. In "Results" section are shown the failure points simulated on stress-strain diagrams with the further described meshes.

Table 3 IM7-8552 material properties used to compute the failure envelopes using the IQC

\begin{tabular}{lll}
\hline Property & Value (MPa) & References \\
\hline$X_{T}$ & 2323.5 & {$[25]$} \\
$X_{C}$ & -1017.5 & {$[25]$} \\
$Y_{T}$ & 62.3 & {$[26]$} \\
$Y_{B T}$ & 37.8 & {$[1]$} \\
$Y_{C}$ & -253.7 & {$[2]$} \\
$Y_{B C}$ & -600.0 & {$[1]$} \\
$S_{L}$ & 89.6 & {$[25]$} \\
$S_{T}$ & 62.3 & {$[26]$} \\
\hline
\end{tabular}




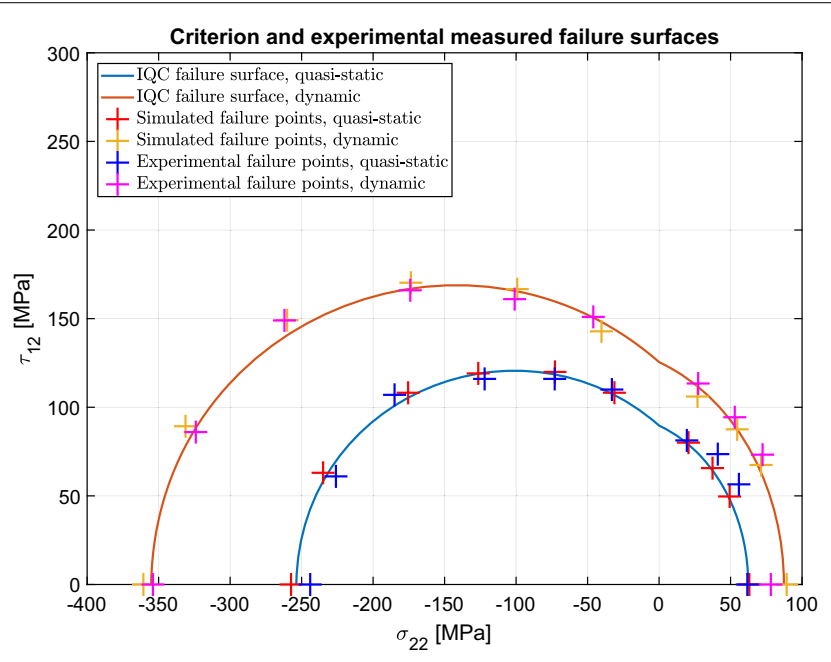

Fig. 6 Failure surfaces and points, experimental and simulated (true stress used for experimental data points)

\section{Material data and calibration of the viscoplastic parameters}

Hereafter, the material data preparation using the test data and the calibration of the viscoplastic model parameters are briefly discussed.

\section{Nonlinear behavior and hardening curves}

The material model can represent hardening behavior in 6 stress states, as already explained above. The in-plane shear behavior is obtained using the off-axis tensile and offaxis compression tests. The conversion from the measured axial stress-strain curves into the shear stress-shear strain curves, while accounting for the fiber rotations is described in detail in $[2,21]$. Considering the $15^{\circ}, 30^{\circ}$ and $45^{\circ}$ off-axis compression tests, the corresponding shear curves are nearly congruent, which is described by [2] postulating a master shear curve or representative shear curve. As shown in Fig. 4, such a master shear curve or representative shear curve can also be obtained from the $15^{\circ}, 30^{\circ}$ and $45^{\circ}$ off-axis tension tests. However, the representative shear curve for tensile loading is lower than the representative shear curve for compressive loading. The reason for this is the influence of hydrostatic pressure on the yielding behavior. All off-axis tests are superimposed with hydrostatic pressure and, thus, the conversion into shear stress-shear strain curves does not represent a pure in-plane shear stress state. Since such a pure in-plane shear stress state is not obtained in the experiments, the in-plane shear stress state is assumed to be a mean value of the representative shear curves obtained from the off-axis tensile and from the off-axis compression tests. Figure 7 shows shear curves, obtained from the representative quasi-static off-axis tension and compression tests, as well as the assumed in-plane shear behavior for pure shear loading.

The transverse compression hardening curve was directly obtained from the transverse compression test [2]. The transverse shear hardening curve is assumed to be similar to the in-plane shear behavior [21], because the transverse shear behavior is not very sensitive in the off-axis and transverse compression and tension tests. For a more detailed examination, the transverse shear behavior could be calibrated using 3 point bending tests with a relatively low span length. 


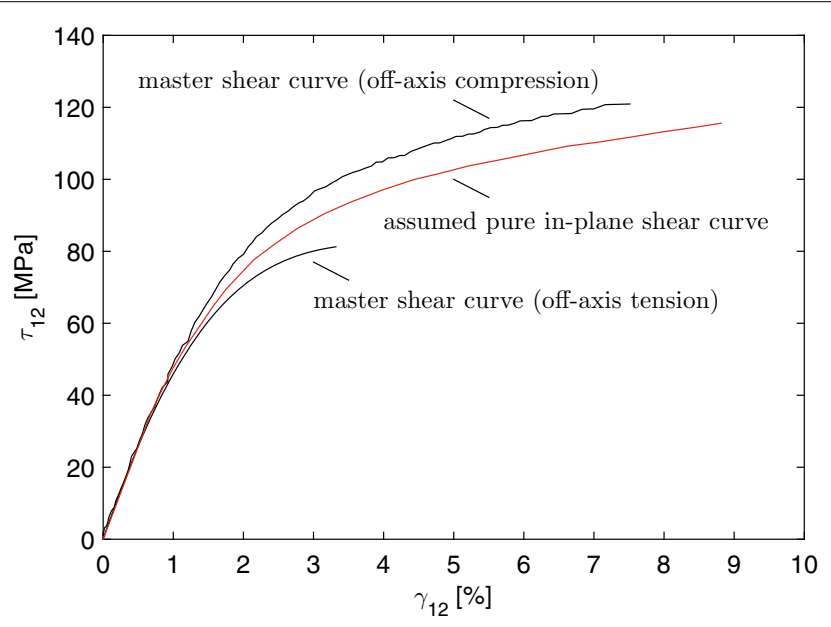

Fig. 7 Quasi-static in-plane shear behavior, deduced from off-axis tensile and off-axis compression tests (engineering stress-strain curves shown)

Under uniaxial transverse tension, approximately linear elastic behavior until fracture is generally observed in the material tests. However, nonlinearity in transverse tension must be defined in order to trigger the nonlinear behavior for combined shear-tensile stress states $\left(15^{\circ}, 30^{\circ}, 45^{\circ}\right.$ off-axis tests). That is, although nonlinear behavior is negligible under pure uniaxial tension, a hypothetic tensile hardening curve (see Fig. 8) is required. For this purpose, a tensile hardening curve is derived using a data reduction procedure for the plasticity model proposed by [27]. The hypothetical transverse tensile hardening curve is schematised in Fig. 8. That Figure must only be considered as an ideal representation of the axial behavior, for which the failure during the tests occurs too early to observe a proper hardening. In the proposed model, biaxial hardening curves can also be represented, but they are not sensitive in the off-axis compression and off-axis tensile tests, since the triaxiality is relatively low in these tests. It is important to note that the model requires only the quasi-static hardening data, and that this data is used regardless of the strain-rate. It is via the viscoplastic formulation only that the plastic yield will depend on the strain rate.

\section{Calibration of viscoplasticity parameter $\mathrm{m}$ and $\eta$}

The calibration of the two viscoplastic parameters $m$ and $\eta$ of the Perzyna type overstress model introduced in Eq. (18) is briefly discussed. For the current material IM7-8552, just two strain rate regimes are tested. Consequently, the parameter $m$ is set to $m=1$ and an approximately linear dependency of the viscoplastic yield stress on the logarithmic strain rate can be modelled using the parameter $\eta$. Although such a linear dependency from the logarithmic strain rate for carbon-epoxy is reported by [28], it cannot be assumed for arbitrary matrix materials. Thermoplastics for instance, or thermoplastic toughened resins exhibit a nonlinear dependency on the logarithmic strain rate [21]. To account for this nonlinear dependency, the parameter $m$ of the viscoplastic model can be used. Therefore, test data for at least 3 strain rate regimes are required for a calibration of the parameter $m$. 


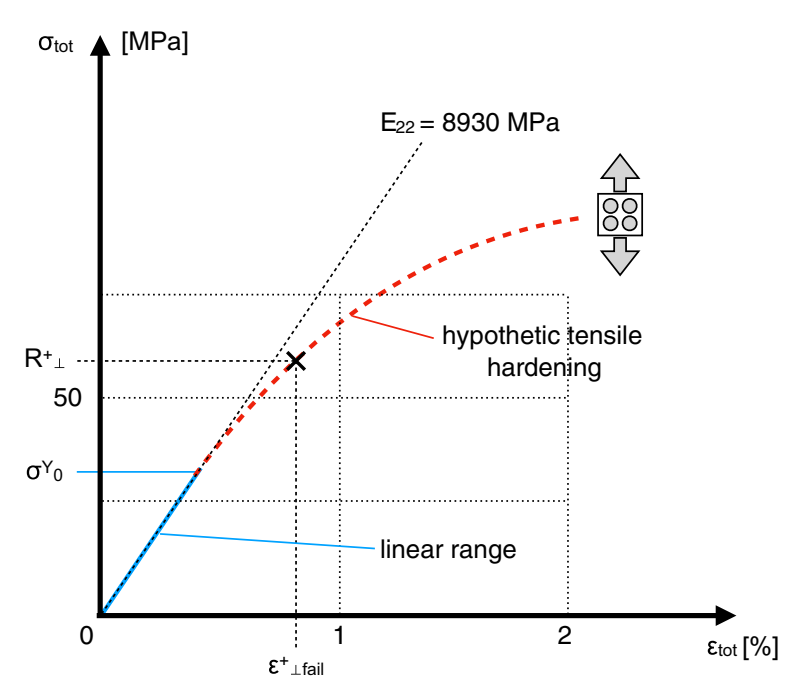

Fig. 8 Nonlinear stress-strain curve for transverse tension

Table 4 IM7-8552 elastic properties used by the model

\begin{tabular}{ll}
\hline Property & Value \\
\hline$E_{1}$ & $171,420 \mathrm{MPa}$ \\
$E_{2}$ & $8930 \mathrm{MPa}$ \\
$G_{12}$ & $5100 \mathrm{MPa}$ \\
$\nu_{12}$ & 0.01667 \\
$\nu_{23}$ & 0.34 \\
\hline
\end{tabular}

To calibrate the remaining viscoplastic parameter $\eta$, the axial stress-strain curves from the $45^{\circ}$ off-axis compression tests are used. These tests were performed at two different strain rates, at quasi-static rate $\left(0.0004 \mathrm{~s}^{-1}\right)$ and at an axial strain rate of approximate $280 \mathrm{~s}^{-1}$. The calibration is done with a simple approximation of $\eta$ using a single element test and finally checked using a fine mesh, whereby the parameter $\eta=4.0 \mathrm{E}-4 \mathrm{Ns} \mathrm{mm}^{2}$ gives the best approximation. It is assumed that the viscosity is independent from the hydrostatic pressure and, hence, the strain rate dependency on the yielding behavior is similar both in tension and in compression.

\section{Calibration of the scaling functions}

The parameters used in the scaling functions, to fit the strain rate dependency of the elastic and ultimate strength properties with the experimental data are the following [20],

$$
\begin{array}{ccc}
f_{e}(\dot{\boldsymbol{\varepsilon}})=1+\left(K_{e} \dot{\boldsymbol{\varepsilon}}\right)^{\frac{1}{n_{e}}}, & K_{e}=1.60 \times 10^{-4}, & n_{e}=2, \\
f_{u}(\dot{\boldsymbol{\varepsilon}})=1+\left(K_{u} \dot{\boldsymbol{\varepsilon}}\right)^{\frac{1}{n_{u}}}, & K_{u}=1.13 \times 10^{-4}, & n_{u}=4 .
\end{array}
$$

\section{Elastic properties}

The elastic properties used in the numerical model are taken from the literature [21] and they are presented in Table 4. 


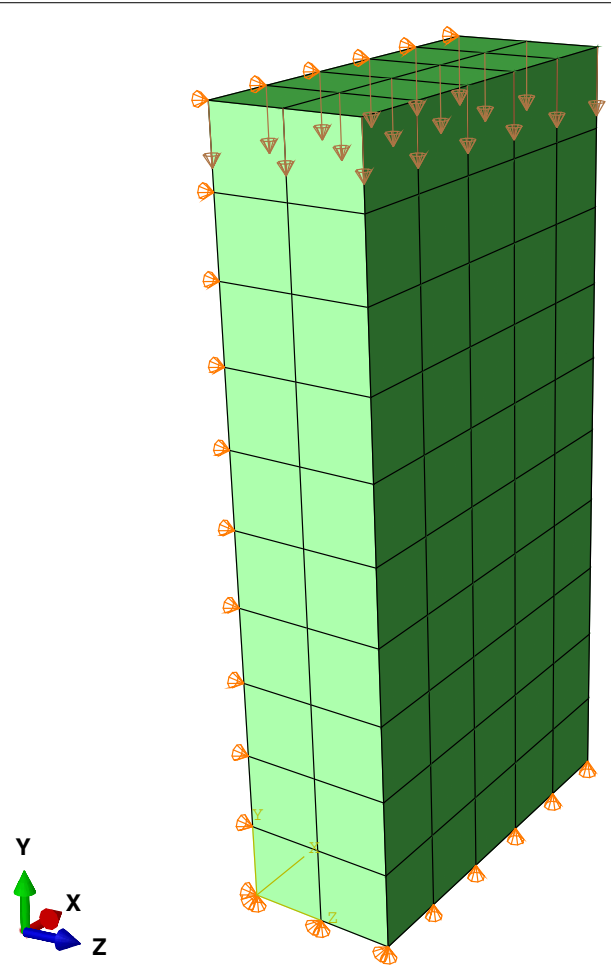

Fig. 9 Medium mesh and boundary conditions for a compression simulation

\section{Results}

\section{Meshes and boundary conditions}

Figure 9 shows the mesh and the boundary conditions used for the compression simulations. The simulations are done with the finite element commercial software ABAQUS/Explicit, where the material behavior is implemented as a VUMAT. For the tensile loading simulations, the mesh is different because the specimen dimensions are different, but the boundary conditions are similar (with the displacement imposed in the opposite direction). Three-dimensional, eight-node C3D8R solid elements with reduced integration are used throughout the model. It appears that for the simulations using a fine or medium mesh or even a single element mesh provide very close results. This assessment can be observed in Fig. 10 for the $45^{\circ}$ off-axis compression simulation (and is generalised for the other loading scenarios). For that reason, the prediction results presented hereafter have been obtained via simulation on a medium mesh for the quasi-static loads and a fine mesh for the dynamic loads (see Fig. 11). As the material model is an homogenised model at the laminate level, it can be applied to a single specimen-sized element, or to a more refined mesh. Here, only two elements are used in the thickness to assess that the material response is more or less the same in the thickness, and the simulations prove that assumption to be true. Furthermore, using only one element in the thickness has a negligible effect on the prediction and can reduce the computation duration if needed.

It is noted that in [2] the experimental data was presented with engineering stresses. For a correct comparison with the axial stress-strain curves predicted by the model and for which true stress is used, the experimental stress-strain curves from [2] are shown with true stress as well. For the conversion from engineering to true stress, again the volume 


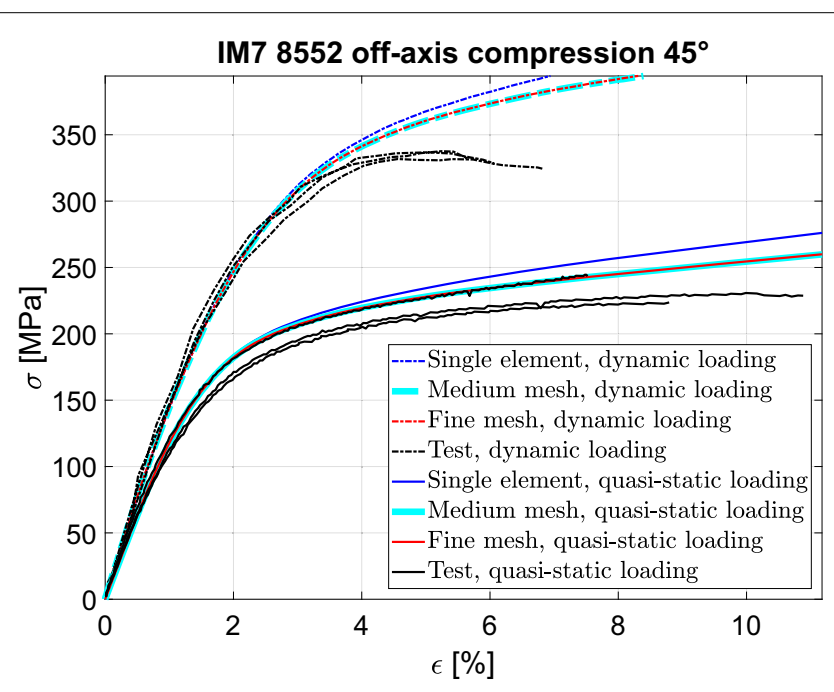

Fig. 10 Comparison of the axial stress/strain prediction using different meshes during dynamic and quasi-static simulations
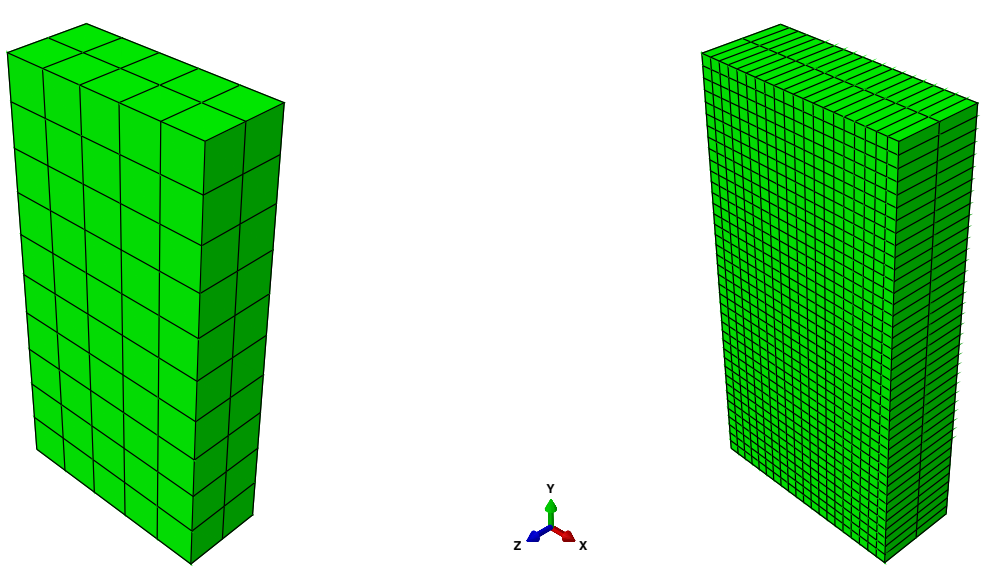

Fig. 11 Medium and fine meshes used for the compression simulations

consistency condition was used. The method used to read the axial stress and strain in the specimen in the simulation is the same for all the specimens. The axial true strain, computed using the value of the axial displacement of the free extremity of the specimen reads

$$
\varepsilon_{\text {axial }, \text { true }}=\log \left(1+\frac{\Delta l}{l_{0}}\right)=\log \left(\frac{l}{l_{0}}\right) .
$$

The axial stress is then computed by reading the sum of the reaction forces at the end of the specimen and using the value of the axial technical strain and the initial section as follows

$$
\sigma_{\text {axial, true }}=\frac{P}{A_{0}}\left(1+\frac{l}{l_{0}}\right),
$$

with

$$
P=\sum \text { Reaction forces. }
$$


In Eq. 32, the hypothesis of incompressibility of the material is applied to estimate the current cross section using the axial deformation value. This condition reads

$$
A=A_{0} \frac{l_{0}}{l}=A_{0}\left(1+\frac{\Delta l}{l_{0}}\right)^{-1}
$$

In the following figures, black color is used for the experimental curves while red color is used for the simulation curves. The blue crosses correspond to the failure points obtained using the IQC.

\section{Tension results}

Figures 12, 13, 14 and 15 show the measured and simulated static and dynamic axial stress-strain curves under $15^{\circ}, 30^{\circ}, 45^{\circ}$ off-axis tension and $90^{\circ}$ transverse tension. For the $15^{\circ}$ specimen type, the comparison between experiment and simulation is quite good. Considering the experimental data of the dynamic $30^{\circ}, 45^{\circ}$ and $90^{\circ}$ off-axis and transverse

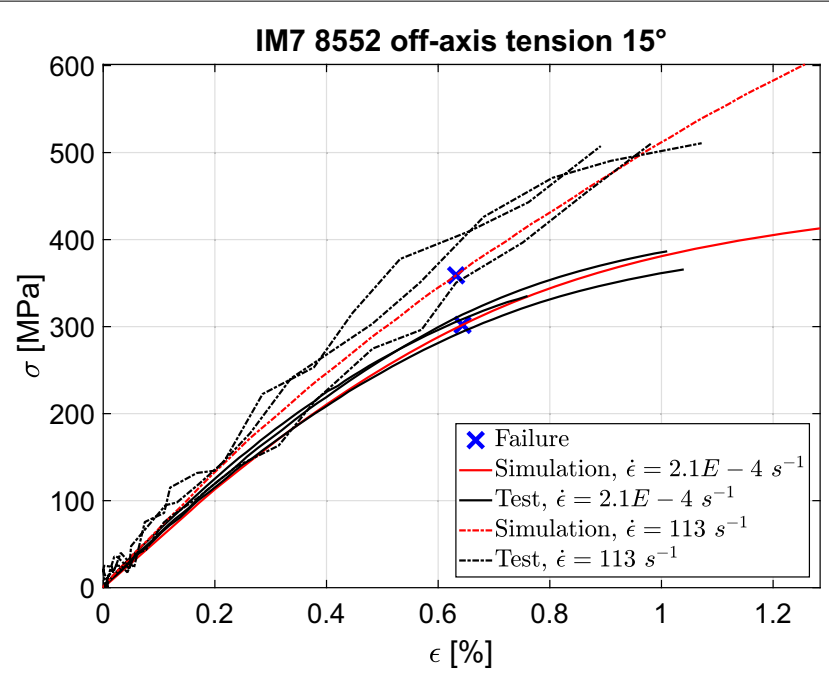

Fig. 12 True stress-true strain curves for the tensile tests and simulations, $15^{\circ}$

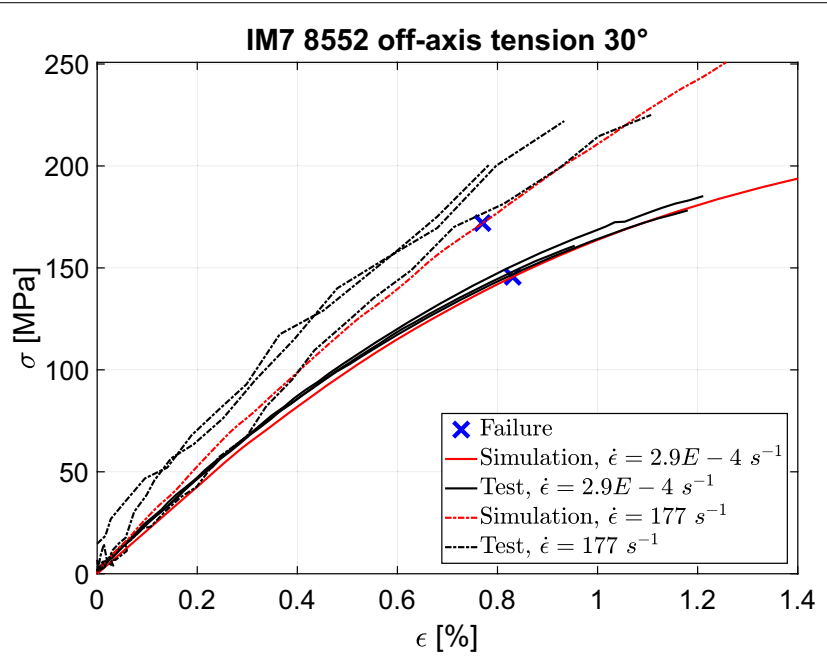

Fig. 13 True stress-true strain curves for the tensile tests and simulations, $30^{\circ}$ 


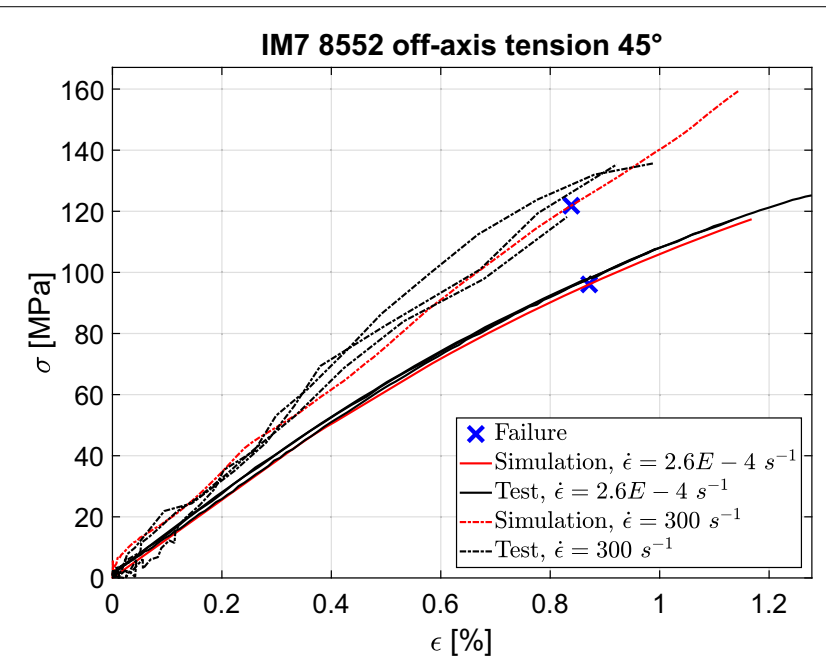

Fig. 14 True stress-true strain curves for the tensile tests and simulations, $45^{\circ}$

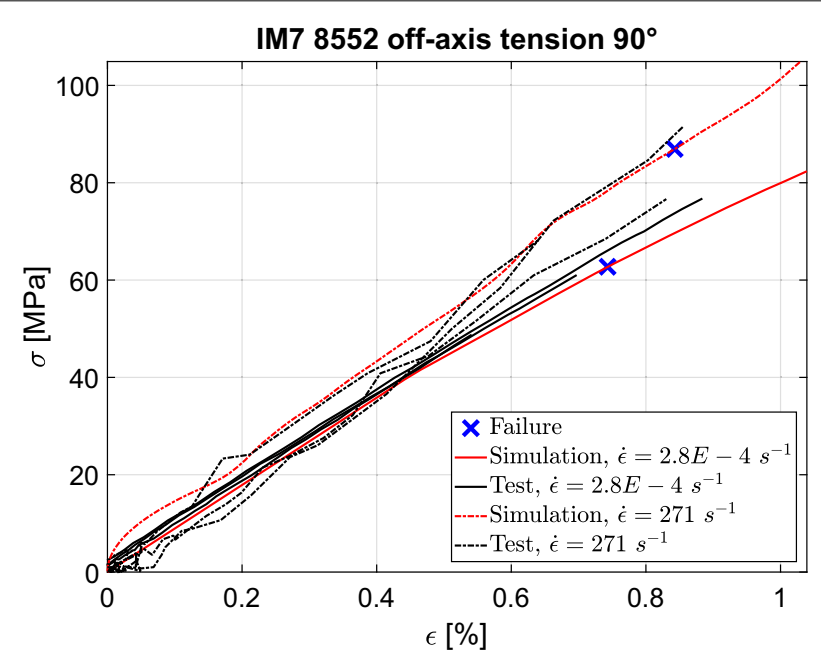

Fig. 15 True stress-true strain curves for the tensile tests and simulations, $90^{\circ}$

tensile tests shown in Figs. 13, 14 and 15, it can be seen that with a higher strain rate the initial slope increases too. It means that viscous effects are also observed in the elastic range and this is well taken into account by the model via scaling functions.

The stress-strain curves become more linear under dynamic loading (see Figs. 12, 13, 14, 15). The present model provides strain-stress curves which match the experimental ones accurately. The viscous effects noticed in both, elastic and plastic range are correctly predicted for the four orientations, validating the model for tensile simulations.

The model predicts ultimate strength using the IQC [11,24]. The measured axial strength increases by 38,28 and $30 \%$ for the $15^{\circ}, 30^{\circ}$ and $45^{\circ}$ off-axis specimen type, respectively under dynamic loading. This tendency is well taken into account by the scaling function. However, the quality of the failure prediction in terms of stress level is not accurate enough and the experimental variability is important here. On the following curves can be observed the quality of the failure prediction in term of the stress level at 
failure. The IQC only predict here the ultimate failure of the element, when one element reaches the criterion, the simulation is stopped (deleting the element lead to the same brutal interruption because when one element is removed, the others remaining fail in the next step). By doing so, the damage propagation is not allowed so the final failure of the specimen can be a bit untimely.

\section{Compression results}

Figures 16, 17, 18, 19, 20 and 21 show the measured and predicted axial stress-strain curves for $15^{\circ}, 30^{\circ}, 45^{\circ}, 60^{\circ}, 75^{\circ}$ off-axis compression and $90^{\circ}$ transverse compression under quasi-static and dynamic loading. Generally, a good prediction of the nonlinear behavior has been achieved for both, quasi-static and dynamic loading case. For compression loading as for the tensile loading, the viscous effects are well taken into account

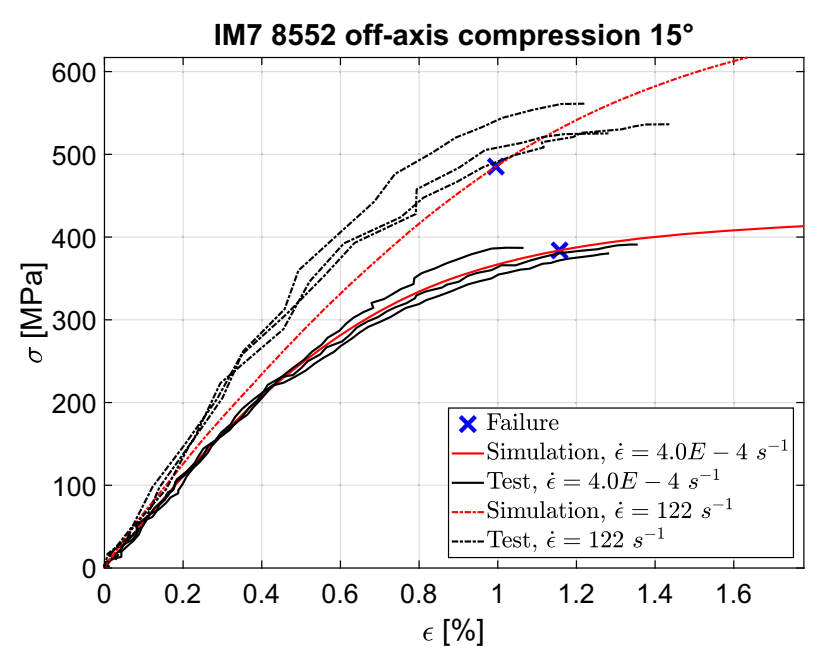

Fig. 16 True stress-true strain curves for the compression tests and simulations, $15^{\circ}$

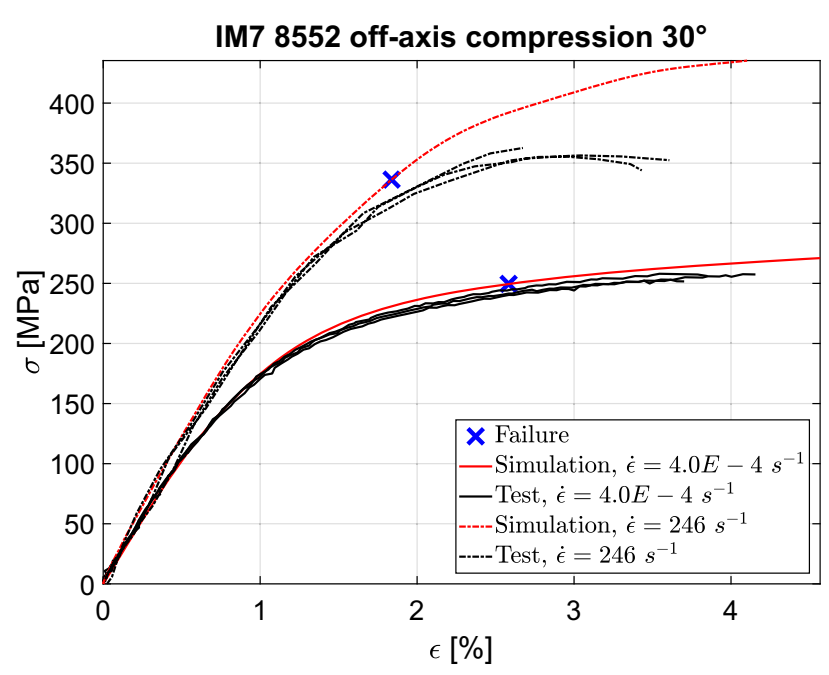

Fig. 17 True stress-true strain curves for the compression tests and simulations, $30^{\circ}$ 


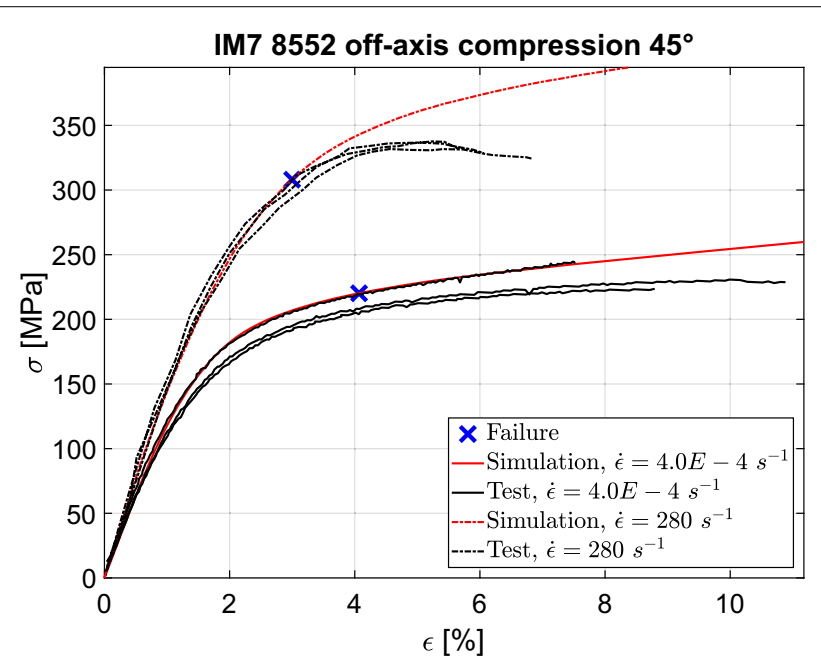

Fig. 18 True stress-true strain curves for the compression tests and simulations, $45^{\circ}$

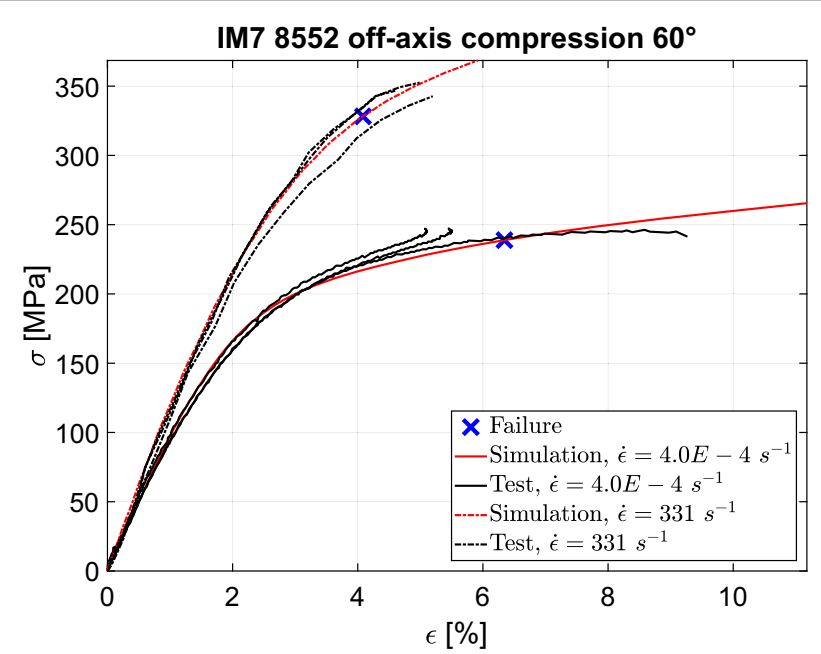

Fig. 19 True stress-true strain curves for the compression tests and simulations, $60^{\circ}$

by the presented model and the scaling functions, allowing a correct prediction of the stress-strain behavior.

It is to be noted that the prediction for the quasi-static cases are very accurate. Dynamic curves are generally good but are too steep where they should tend to be flat (e.g. $15^{\circ}, 30^{\circ}$ and $45^{\circ}$ ). The IQC provides good predictions in term of stress levels at ultimate failure.

\section{Summary and conclusion}

The viscoplastic behavior of the IM7-8552 carbon-epoxy was investigated using off-axis and transverse tension and compression tests under quasi-static $\left(0.0004 \mathrm{~s}^{-1}\right)$ and dynamic (113-300 s $\left.{ }^{-1}\right)$ loading. The available off-axis and transverse tension and compression test data was simulated using a fully $3 \mathrm{D}$ transversely isotropic elastic-viscoplastic constitutive model, able to predict nonlinearities under off-axis loading conditions prior to the onset of cracking. A representative in-plane shear curve for pure shear loading was deduced from 


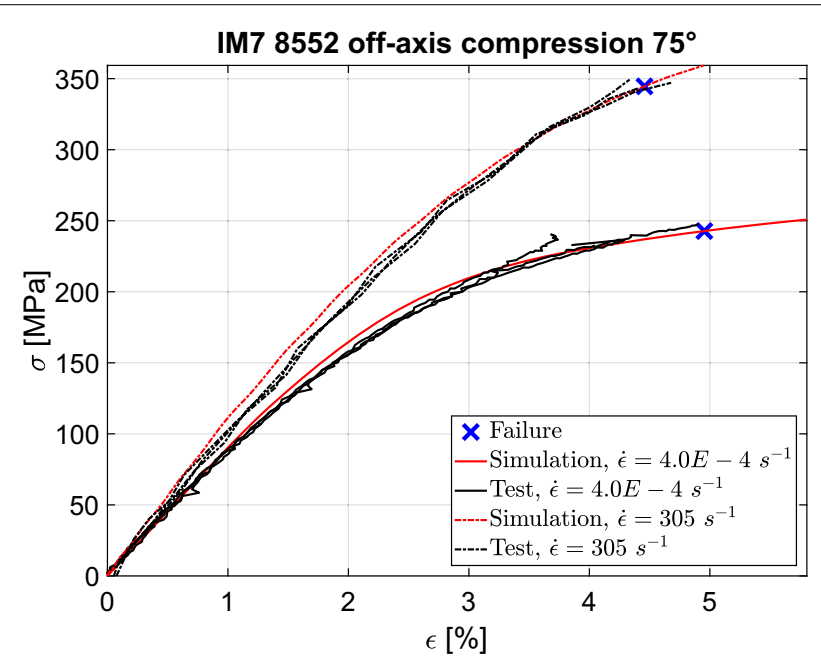

Fig. 20 True stress-true strain curves for the compression tests and simulations, $75^{\circ}$

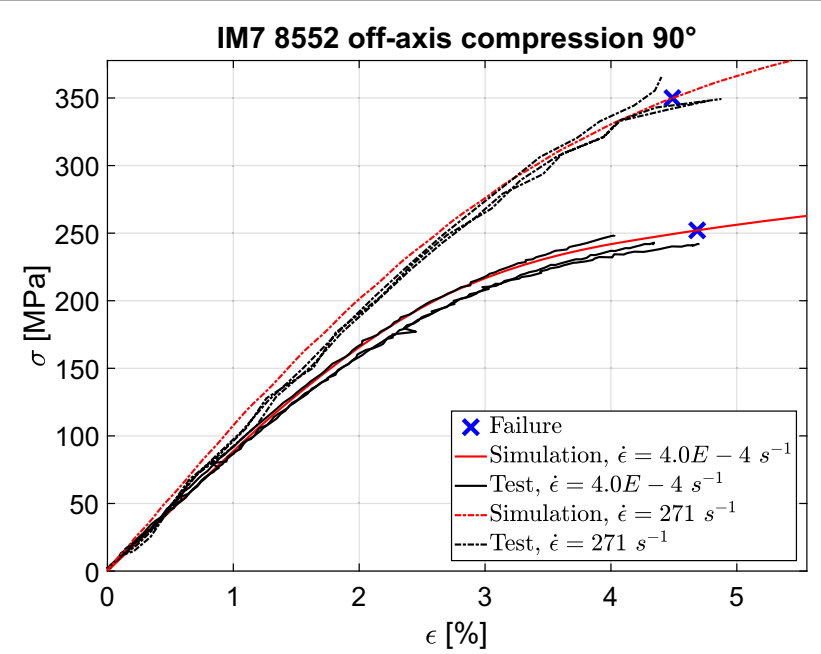

Fig. 21 True stress-true strain curves for the compression tests and simulations, $90^{\circ}$

the available off-axis tension and compression test data and the influence of triaxiality on the in-plane shear characterization was discussed. The calibration of the parameter $\eta$ of the presented viscoplastic model was shown, assuming an approximated linear dependency of the yield stress on the logarithmic strain rate, since experimental data was available from only two strain rate regimes. The strain rate dependency of the elastic moduli and the ultimate strength properties was introduced in the proposed model by fitting the available experimental data with suitable scaling functions. For the prediction of failure, an Invariant based Quadratic failure Criterion (IQC) based on the work of Vogler et al. $[11,24]$ was implemented. The model provides good predictions of the stress-strain state, regardless of the size of the finite elements, meaning that using a single element provides excellent quality results in a very short time. It therefore makes it a very efficient model for stress-strain predictions at the ply scale. The correlation between experimental data and the stress-strain response predicted by the constitutive model was well achieved for all 
specimen types and for both strain rate regimes. A shift from nonlinear to predominantly linear stress-strain response was observed for the dynamic off-axis tensile tests. However, the importance of assuming a nonlinear hardening curve for transverse tension beyond the point of failure in order to predict combined in-plane shear-transverse tensile stress states was discussed. The failure observed in the experiments presented here is caused by matrix failure. An good prediction of the stress level at failure was achieved for both tension and compression simulations.

\section{Authors' contributions}

HK, PK and MP defined, executed and analysed the experimental tests. FO and P-WG defined and implemented the numerical model. RR and PPC supervised the development of the numerical model. All authors contributed to the text presented in the paper. All authors read and approved the final manuscript.

\section{Author details}

${ }^{1}$ Department of Mechanical Engineering, Chair of Carbon Composites, Technical University of Munich, Boltzmannstrasse 15, 85748, Garching bei München, Germany, ${ }^{2}$ INEGI, Rua Dr. Roberto Frias 400, 4200-465 Porto, Portugal, ${ }^{3}$ CIMNE, Centre Internacional de Metodes Numerics en Enginyeria, Gran Capita s/n, 08034 Barcelona, Spain, ENS Cachan, Université Paris-Saclay, Avenue du Président Wilson 61, 94235 Cachan, France, ${ }^{5}$ ISD-Leibniz University of Hannover, Appelstraße 9A, 30167 Hannover, Germany, ${ }^{6}$ DEMec, Faculdade de Engenharia, Universidade do Porto, Rua Dr. Roberto Frias 400, 4200-465 Porto, Portugal.

\section{Acknowledgements}

This paper is dedicated to the memory of Dr. Matthias Vogler, an exceptional young scientist that sadly left us too soon. P. P. Camanho and F. Otero would like to acknowledge the funding of Project NORTE-01-0145-FEDER-000022-SciTechScience and Technology for Competitive and Sustainable Industries, co-financed by Programa Operacional Regional do Norte (NORTE2020), through Fundo Europeu de Desenvolvimento Regional (FEDER).

\section{Competing interests}

The authors declare that they have no competing interests.

Availability of data and materials

Not applicable.

\section{Consent for publication}

Not applicable.

Ethics approval and consent to participate

Not applicable.

Funding

Not applicable.

\section{Publisher's Note}

Springer Nature remains neutral with regard to jurisdictional claims in published maps and institutional affiliations.

Received: 21 February 2018 Accepted: 18 June 2018

Published online: 28 June 2018

\section{References}

1. Vogler M, Rolfes R, Camanho PP. Modeling the inelastic deformation and fracture of polymer composites-part I: plasticity model. Mech Mater. 2013:59:50-64. https://doi.org/10.1016/j.mechmat.2012.12.002.

2. Koerber H, Xavier J, Camanho PP. High strain rate characterisation of unidirectional carbon-epoxy IM7-8552 in transverse compression and in-plane shear using digital image correlation. Mech Mater. 2010;42(11):1004-19. https://doi.org/10.1016/J.MECHMAT.2010.09.003

3. Koerber $\mathrm{H}$, Camanho PP. High strain rate characterisation of unidirectional carbon-epoxy im7-8552 in longitudinal compression. Compos Part A Appl Sci Manuf. 2011;42(5):462-70. https://doi.org/10.1016/j.compositesa.2011.01.002.

4. Ploeckl M, Kuhn P, Grosser J, Wolfahrt M, Koerber H. A dynamic test methodology for analyzing the strain-rate effect on the longitudinal compressive behavior of fiber-reinforced composites. Compos Struct. 2017;180:429-38. https:// doi.org/10.1016/j.compstruct.2017.08.048.

5. Kuhn P, Catalanotti G, Xavier J, Camanho PP, Koerber H. Fracture toughness and crack resistance curves for fiber compressive failure mode in polymer composites under high rate loading. Compos Struct. 2017;182:164-75. https:// doi.org/10.1016/j.compstruct.2017.09.040.

6. Gerlach R, Kettenbeil C, Petrinic N. A new split hopkinson tensile bar design. Int J Impact Eng. 2012;50:63-7. https:// doi.org/10.1016/j.ijimpeng.2012.08.004. 
7. Koerber H, Xavier J, Camanho PP, Essa YE, de la Escalera FM. High strain rate behaviour of 5-harness-satin weave fabric carbon epoxy composite under compression and combined compression shear loading. Int J Solids Struct. 2015;54:172-82. https://doi.org/10.1016/j.ijsolstr.2014.10.018.

8. Gray GT III. Classic split-Hopkinson pressure bar testing. In: Kuhn H, Medlin D, editors. ASM handbook vol 8 mechanical testing and evaluation. Russell: ASM Int; 2000. p. 462-76.

9. Kuhn P, Ploeckl M, Koerber H. Experimental investigation of the failure envelope of unidirectional carbon-epoxy composite under high strain rate transverse and off-axis tensile loading. EPJ Web Conf. 2015;94:01040. https://doi. org/10.1051/epjconf/20159401040.

10. Hexcel: HexPly R 8552-Product Data Sheet-EU Version. 2016.

11. Vogler M, Ernst G, Rolfes R. Invariant based transversely-isotropic material and failure model for fiber-reinforced polymers. Compute Mater Contin. 2010;16(1):25-49.

12. Gilat A, Goldberg RK, Roberts GD. Experimental study of strain-rate-dependent behavior of carbon/epoxy composite. Compos Sci Technol. 2002;62(10-11):1469-76. https://doi.org/10.1016/S0266-3538(02)00100-8.

13. Taniguchi N, Nishiwaki T, Kawada H. Tensile strength of unidirectional CFRP laminate under high strain rate. Adv Compos Mater. 2007;16(2):167-80. https://doi.org/10.1163/156855107780918937.

14. Lifshitz JM, Leber $H$. Response of fiber-reinforced polymers to high strain-rate loading in interlaminar tension and combined tension/shear. Compos Sci Technol. 1998;58(6):987-96. https://doi.org/10.1016/S0266-3538(97)00226-1.

15. Hsiao HM, Daniel IM, Cordes RD. Strain rate effects on the transverse compressive and shear behavior of unidirectional composites. J Compos Mater. 1999;33(17):1620-42. https://doi.org/10.1177/002199839903301703.

16. Hosur MV, Alexander J, Vaidya UK, Jeelani S. High strain rate compression response of carbon/epoxy laminate composites. Compos Struct. 2001;52(3-4):405-17. https://doi.org/10.1016/S0263-8223(01)00031-9.

17. Bing $Q$, Sun CT. Modeling and testing strain rate-dependent compressive strength of carbon/epoxy composites. Compos Sci Technol. 2005;65(15-16):2481-91. https://doi.org/10.1016/J.COMPSCITECH.2005.06.012.

18. Naik NK, Asmelash A, Kavala VR, Ch V. Interlaminar shear properties of polymer matrix composites: strain rate effect. Mech Mater. 2007;39(12):1043-52. https://doi.org/10.1016/J.MECHMAT.2007.05.003.

19. Wiegand J. Constitutive modelling of composite materials under impact engineering science. Oxford: University of Oxford; 2008.

20. Koerber H. Mechanical response of advanced composites under high strain rates. Ph.D. thesis, Faculdade de Engenharia da Universidade do Porto, Departamento de Engenharia Mecanica. 2010.

21. Vogler M. Anisotropic material models for fiber reinforced polymers. Ph.D. thesis, Mitteilungen des Instituts für Statik und Dynamik der Leibniz Universität Hannover. 2012.

22. Perzyna P. The constitutive equations for rate sensitive plastic materials. Q Appl Math. 1963;20(4):321-32. https://doi. org/10.2307/43636430.

23. Maugin GA. The thermomechanics of plasticity and fracture. Cambridge: Cambridge University Press; 1992. https:// doi.org/10.1017/CBO9781139172400.

24. Camanho PP, Arteiro A, Melro AR, Catalanotti G, Vogler M. Three-dimensional invariant-based failure criteria for fibre-reinforced composites. Int J Solids Struct. 2015:55:92-107. https://doi.org/10.1016/j.ijsolstr.2014.03.038.

25. Catalanotti G, Camanho PP, Marques AT. Three-dimensional failure criteria for fiber-reinforced laminates. Compos Struct. 2013;95:63-79. https://doi.org/10.1016/j.compstruct.2012.07.016.

26. Camanho PP, Lambert M. A design methodology for mechanically fastened joints in laminated composite materials. Compos Sci Technol. 2006;66(15):3004-20. https://doi.org/10.1016/j.compscitech.2006.02.017.

27. Sun CT, Chen JL. A simple flow rule for characterizing nonlinear behavior of fiber composites. J Compos Mater. 1989;23(10):1009-20. https://doi.org/10.1177/002199838902301004.

28. Schaefer JD, Werner BT, Daniel IM. Strain-rate-dependent failure of a toughened matrix composite. Exp Mech. 2014;54(6):1111-20. https://doi.org/10.1007/s11340-014-9876-0.

\section{Submit your manuscript to a SpringerOpen ${ }^{\circ}$ journal and benefit from:}

- Convenient online submission

- Rigorous peer review

- Open access: articles freely available online

- High visibility within the field

- Retaining the copyright to your article

Submit your next manuscript at springeropen.com 